Instructions for authors, subscriptions and further details:

\title{
Performing American Masculinities: The 21st-Century Man in Popular Culture
}

Sandra Girbés ${ }^{1}$

1) Universitat de Barcelona, Spain

Date of publication: June $21^{\text {st }}, 2014$

Edition period: June 2014-October 2014

To cite this article: Girbés, S. (2014) Performing American Masculinities: The 21st-Century Man in Popular Culture. Masculinities and Social Change, 3(2), 191-193. doi: 10.4471/MCS.2014.50

To link this article: http://dx.doi.org/10.4471/MCS.2014.50

\section{PLEASE SCROLL DOWN FOR ARTICLE}

The terms and conditions of use are related to the Open Journal System and to Creative Commons Attribution License (CC-BY). 
MSC-Masculinities and Social Change Vol. 3 No. 2 June 2014 pp. 191-193

\section{Reviews (I)}

Watson, E. \& Shaw, M. (Eds.) (2011). Performing American Masculinities: The 21st-Century Man in Popular Culture. Bloomington and Indianapolis: Indiana University Press. ISBN 978-0253222701

El libro Performing American Masculinities aporta una serie de ensayos que evidencian los cambios experimentados en las representaciones de la masculinidad a través del análisis de programas televisivos, películas, anuncios, obras teatrales, literatura, eventos políticos, música, fotografías o contenidos de Internet producidos en el contexto norteamericano entre mediados de 1990 y 2010. El conjunto de ensayo parte de la relación existente entre los cambios sociales experimentados a nivel global durante este período y los diversos modelos de masculinidad generados como respuesta a las modificaciones identificadas en el espacio, el tiempo y en las relaciones interpersonales. Partiendo de la premisa de que los acontecimientos históricos modifican los procesos de construcción del género y de las identidades individuales, se presta especial atención a dos sucesos a los que se les ha atribuido un elevado valor real y simbólico en el contexto norteamericano: la crisis financiera iniciada en 2008 y la elección del presidente Barack Obama. Estos eventos conectan con las dos ideas centrales que articulan el libro.

El primer capítulo, titulado Masculinities and the Market: Late Capitalism and Corporate Influence on Gender Processes y formado por cuatro ensayos, aborda la influencia que la coyuntura económica ejerce en la formación y en la reconfiguración de la masculinidad. En esta parte de la obra se aportan diversas perspectivas sobre las influencias ejercidas por el sistema económico abordando temáticas como la intervención del mercado de trabajo en la construcción del género, la regulación que el capitalismo tardío ejerce sobre la sexualidad o aportando una perspectiva de género a la agencia de los sujetos frente a los problemas financieros.

En el capítulo Masters of Their Domain: Seinfeld and the Discipline of Mediated Men's Sexual Economy, Wesley Buerkle parte del análisis de la serie Seinfeld y del programa Queer Eye for the Straight Guy para analizar 
la tensión surgida entre la masculinidad en la sociedad industrial, basada en la sobriedad y en la productividad, y la emergencia de un nuevo modelo en la era neoliberal que pone el énfasis en el consumo y en la autocomplacencia.

Brenda Boudreau, en el capítulo Sexually Suspect: Masculine Anxiety in the Films of Neil LaBute, identifica el surgimiento de una crisis de la masculinidad entre finales del siglo XX y principios del siglo XXI. Como resultado, muchos hombres deben enfrentarse a las inseguridades generadas por la pérdida de una noción clara de masculinidad y a las expectativas sociales en relación con su vida pública o sexual.

Por otro lado, las aportaciones de Margaret C. Ervin en el capítulo The Might of the Metrosexual: How a Mere Marketing Tool Challenges Hegemonic Masculinity se centran en el fenómeno de la metrosexualidad. La autora argumenta que lo que comenzó como una estrategia de mercado de las grandes empresas ha sido utilizado para generar nuevas formas de vivir la masculinidad que se oponen a los modelos hegemónicos.

La segunda parte del libro, titulada Beyond Gender Alone: Defining Multidimensional Masculinities y compuesta por cinco ensayos, se centra en la masculinidad como resultado de la intersección de varios factores incluyendo étnia, religión, diversidad funcional, sexualidad y transgénero. Uno de los personajes públicos a los que se dirige la atención en esta parte del libro es el presidente de los Estados Unidos Barck Obama. En el capítulo Obama's Masculinities: A Landscape of Essential Contradictions, Mac E. Shaw y Elwood Watson abordan cómo la figura del presidente abre un interesante debate sobre étnia, poder y género. El análisis de las representaciones mediáticas de Barack Obama, personaje publico al que se le atribuye una masculinidad ambigua e incluso feminizada, da paso a profundizar sobre las creencias e imaginarios vinculados a la masculinidad de los hombres afroamericanos.

La perspectiva étnica y cultural también es abordada en el capítulo elaborado por John Kille, Popular Memory, Racial Construction, and the Visual Illusion of Freedom: The Re-mediation of O.J. and Cinque. Partiendo de la escena del juicio que inicia la película Amistad de Steven Spielberg, el autor reflexiona en torno al papel de los medios de comunicación en la transmisión de la desigualdad entre hombres blancos y negros a lo largo de la historia norteamericana. 
Girbés - Performing American Masculinities [Book Review] 193

Performing American Masculinities ofrece un amplio repertorio de investigaciones sobre cultura popular norteamericana y estudios de género en el contexto capitalista que nos permiten romper con concepciones estáticas de la masculinidad. Además, este libro apunta hacia nuevos escenarios y disciplinas, evidenciando la necesidad de seguir generando diálogos e investigaciones multidisciplinares en torno a las masculinidades.

Sandra Girbés, Universitat de Barcelona sandra.girbes@gmail.com 